\title{
ESTÁGIO CURRICULAR SUPERVISIONADO: PERCEPÇÕES SOBRE A ETAPA DE CARACTERIZAÇÃO DA ESCOLA
}

\author{
PRÁCTICA CURRICULAR SUPERVISIONADA: \\ PERCEPCIONES SOBRE LA ETAPA DE CARACTERIZACIÓN \\ ESCOLAR
}

Ana Caroline Souza de Oliva ${ }^{1}$ Valéria Daiane Soares Rodrigues ${ }^{2}$

\begin{abstract}
RESUMO
Este trabalho apresenta um relato de experiência propiciado pelo Estágio Curricular Supervisionado - etapa de caracterização da escola. Objetivou-se analisar a organização administrativa de uma escola de Montes Claros que oferece apenas o ensino fundamental e como esta atua no comportamento e desenvolvimento dos alunos. Para que esta pesquisa fosse realizada, a metodologia constituiu-se de observação da escola em diferentes momentos e leitura dos documentos que estruturam o funcionamento da instituição. Sob essa perspectiva, percebemos a importância do olhar do discente de Letras Espanhol acerca do seu posterior local de atuação profissional de forma a conhecer as particularidades da escola. Além disso, refletir sobre maneiras de implementar projetos que diminuam a distância entre universidade e escola a fim de que exista uma orientação clara frente a presença dos estagiários no ambiente escolar.
\end{abstract}

Palavras-chave: Estágio Supervisionado, Língua Espanhola, Caracterização da escola.

\section{ABSTRACT}

Ese trabajo presenta un relato de experiencia propiciado por las prácticas supervisadas de caracterización de la escuela. El objetivo fue analizar la organización administrativa de una escuela de Montes Claros que ofrece solamente la enseñanza fundamental y como esta actúa en el comportamiento y desarrollo de los alumnos. Para que esta pesquisa fuera realizada, la metodología constituyó de la observación de la escuela en diferentes momentos y lectura de los documentos que estructuran el funcionamiento de la institución. En esta perspectiva, percibimos la importancia de la mirada del discente de Letras Español en relación al futuro local de actuación profesional de forma a conocer las particularidades de la escuela. Además, reflejar sobre maneras de implementar proyectos que reduzcan la distancia entre universidad y escuela a fin de que exista una orientación clara delante de la presencia de los pasantes en el ambiente escolar.

Palabras llave: Prácticas supervisadas, lengua española, caracterización de la escuela.

\footnotetext{
${ }^{1}$ Acadêmica do curso de Letras/Espanhol da Universidade Estadual de Montes Claros UNIMONTES.

${ }^{2}$ Professora Mestre do Departamento de Estágios e Práticas Escolares da Universidade Estadual de Montes Claros- UNIMONTES. E-mail: dai.espanhol@hotmail.com. Lattes: http://lattes.cnpq.br/1846160119169010. ORCID: https://orcid.org/0000-0001-6108-7611.
}

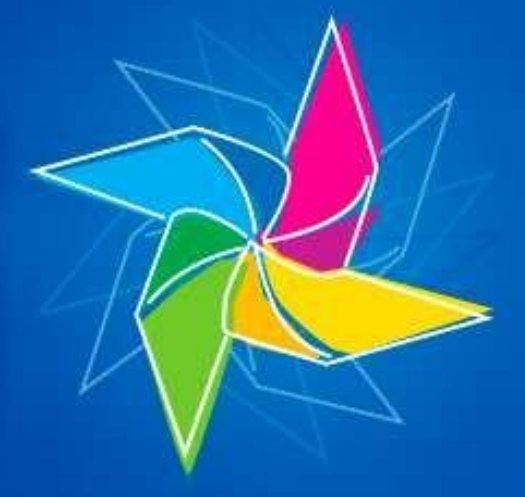




\section{Introdução}

O Projeto Político Pedagógico do curso de Letras Espanhol da Universidade Estadual de Montes Claros - UNIMONTES estabelece quatro etapas para desenvolvimento do estágio curricular supervisionado: caracterização da escola, observação de aulas de língua espanhola no Ensino Fundamente e/ou médio, Regência no Ensino Fundamental e Regência no Ensino Médio. Cada etapa é desenvolvida em um período, começando no quinto e findando-se no oitavo. Diante disso, a etapa de caracterização da escola constitui-se a primeira oportunidade de vivenciar e perceber a escola com olhos de "espectador", um olhar diferenciado em relação à experiência anterior como aluno.

Nesse contexto, iniciar o Estágio Curricular Supervisionado na etapa de caracterização da escola mostrou-se um desafio multifacetado, em especial para acadêmicos que estão na condição de aluno do curso de Letras Espanhol, cuja disciplina não é ofertada na maioria das escolas de educação básica.

Considerando os apontamentos acima elencados, por meio deste artigo, faremos um relato sobre as experiências vivenciadas na escola e compartilhadas no âmbito da Universidade. O artigo está estruturado pelos tópicos a seguir: Caracterizando a escola, Trânsito pelos Espaços da Escola: da porta de Entrada à Diretoria, Hora Cívica e Supervisão do Recreio: Relações Interpessoais em Ação, Palestras e Reuniões no Educandário: Projeção de Perspectivas para o Ambiente Escolar e Considerações finais.

\section{Caracterizando a Escola}

A escola em que foi realizado o estágio funciona no endereço atual desde 1927, passando por uma reforma em 1970, entretanto, ainda conserva a arquitetura da época. Tendo em vista tal realidade, é perceptível o efeito dessas estruturas no que compete a momentos como o recreio que é dividido em três partes, visto que o pátio não contempla a quantidade total de alunos. Além disso, a distribuição de salas apresenta-se complexa para quem chega, visto que há salas nos corredores que levam à cantina e não temos indícios de tal realidade quando adentramos o educandário.

Segundo Couto (2016) a didática não se restringe a sala de aula, mas sim a elementos contextuais, condições físicas e materiais que fazem parte da escola e que vão influenciar nas práticas pedagógicas. Nesse sentido, e considerando todas as questões que permeiam o funcionamento da escola, gostaríamos de mencionar inicialmente dois aspectos que 
consideramos importantes: a primeira impressão sobre a chegada dos alunos na escola e uma reflexão sobre os sentimentos que nos rodeiam ao adentrar nesse ambiente da Escola de Educação Básica, como docentes em processo de formação.

Sobre o primeiro aspecto, convém enfocar que assim que os alunos chegam, esperam no espaço compreendido entre o portão principal e a porta que de fato leva ao pátio. Acompanhados de perto pela vice-diretora, os alunos se dirigem em fila, até o pátio, para participarem do momento da oração, ministrado também pela vice-diretora. Esta não utiliza microfone e mediante a crescente quantidade de alunos que se aglomeram em volta do palco, intermediados pelas professoras, começa se destacando com uma música conhecida pela maioria. Contando com a atenção de quem está próximo, logo outras crianças se juntam ao coro e todos conseguem terminar a música e iniciar a oração, também memorizada pelos discentes. Após esse período breve de oração, as turmas vão saindo aos poucos orientadas pelas docentes responsáveis. Convém ressaltar que, apesar de não contarem com os recursos necessários como microfone e som, a prática diária possibilita maior interação entre os alunos que rezam juntos e depois se separam em direção às salas. Além disso, professores, bibliotecárias, secretária e diretora também se encontravam nesse momento, pois, posteriormente, com os horários estipulados para o recreio, esse contato estaria comprometido.

Somada a percepção acima abordada, outro fator que Fazenda (1994) já apontava em O Papel do Estágio nos Cursos de Formação de Professores era a necessidade de orientação e suporte, mecanismos essenciais para transpor a barreira que divide universidade e escola. Nesse sentido, a diretora e supervisora mostraram-se confusas acerca do que seria "apenas" a caracterização da escola, visto que os estagiários presentes anteriormente na instituição acompanhavam as aulas depois da leitura dos documentos pertinentes à organização escolar. Desta relação, a teoria engaja-se a prática tendo em vista o desafio de se fazer compreender dentro do ambiente do estágio em prol do cumprimento das atividades propostas pelo guia intitulado operacionalização do Estágio, documento utilizado pelo professor orientador, da Instituição de Ensino Superior, quanto às ações a serem desempenhadas na escola ao longo do estágio. Nesse contexto, foi perceptível que os profissionais da escola de educação básica não compreendiam e/ou concordavam com a concepção da Instituição de Ensino Superior quanto à necessidade de despender tanto tempo para acompanhar "apenas" o funcionamento da escola.

\section{Trânsito pelos Espaços da Escola: da porta de Entrada à Diretoria}

Adentrando o espaço interno do educandário que oferece as séries iniciais do Ensino 
Fundamental, foi fácil perceber o cenário ameno da instituição. Em frente ao portão principal temos uma praça arborizada que impossibilita o estacionamento de veículos em frente à escola, espaço este amplamente utilizado nas aulas de Educação Física. Vale ressaltar que a escola não possui quadra poliesportiva, apenas um pátio amplo próximo à biblioteca que proporciona a realização de algumas dinâmicas e competições. Voltando-se para o instituto, ao passar pelo portão intermediário que separa o principal do pequeno corredor, observamos o pátio, rodeado por paredes brancas com murais de fotos de alguns alunos em eventos escolares, acenando para o fato de que a escola é viva e carrega em seu ambiente a história de muitas pessoas: professores, alunos, profissionais dos setores administrativos, de serviços gerais, entre outros. Somado a isso, as portas que não estão identificadas na soleira indicando setores administrativos como Diretoria e Secretaria, possuem anexado às portas o nome dos professores responsáveis pela turma no período da manhã, enquanto do lado direito, fixado na parede, a série que ocupa a sala no período vespertino. Essa menção ao nome dos professores nas portas é interessante no sentido de que sugere uma aproximação entre estes e os respectivos alunos.

Em sua estrutura interna, a escola apresenta rampas, mas o que leva alguém do portão principal ao corredor é uma escada que dificulta a autonomia de passagem por alunos cadeirantes ou que precisem de suporte para chegar ao pátio. Contrariando ao que é recomendado quanto à construção de rampas para maior acessibilidade à estrutura educativa, alunos cadeirantes só transpõem essa barreira com o auxílio dos responsáveis em carregar a cadeira da criança. Além da infraestrutura perceptível na entrada do perímetro escolar, as salas se mostram mal distribuídas, visto que em um primeiro momento a visualização que se tem sobre a escola é de que possui dois andares, ou seja, de que teria um espaço adequado. No entanto, considerando o fato de a supervisora ter solicitado que fosse entregue em todas as salas um bilhete com a relação das disciplinas para a semana de provas, foi possível perceber que cinco das dezoito salas operantes na escola receberam o aviso quase na saída dos discentes em decorrência das dificuldades de locomoção percebidas por conta da estrutura escolar inadequada.

Ao vivenciar as primeiras experiências no ambiente escolar, foi possível refletir sobre a fala de Rodrigues (2017) que discute sobre a forma como os estagiários são recebidos na escola de educação básica. Na concepção da professora "a falta de diálogo entre as instituições faz com que muitos estagiários sejam considerados como intrusos nas escolas" (2017, p. 48). Nesse sentido, a dificuldade de entendimento, por parte da escola, quanto à importância do estágio de caracterização tornou os primeiros dias difíceis. A diretora, vice-diretora e 
supervisora não se mostraram a par do papel a ser exercido na etapa de caracterização, dispondo atividades que não estavam dispostas na operacionalização do estágio como o grampeamento de provas e acompanhamento de uma turma na ausência de um professor que precisava votar em uma eleição de colegiado. Este contexto se justifica não só por se mostrar indiferente a presença de um acadêmico até então restrito ao ambiente universitário, mas também por não haver uma preparação do educandário de como atuar para um melhor rendimento do trabalho desenvolvido pelo estagiário, pois:

Há uma grande necessidade de que o estagiário encontre o seu lugar na escola, dentro das relações de que participa e que o Estágio inclua no seu projeto uma proposta de mudança de enfoque, sugerindo que os alunos reconheçam sua própria presença e o seu local do estágio, em vez de focalizarem suas atenções apenas nos fracassos encontrados. (LIMA, 2008, p. 200-201)

Deste fragmento, compreende-se como o momento do estágio é essencial para o profissional em formação se localizar no futuro local de trabalho e começar a refletir sobre sua identidade perante estas percepções.

Após observar o momento da oração no qual os professores, seguidos pelos alunos em filas dirigem-se às suas respectivas salas, o guia de operacionalização do estágio indicava para a leitura do Projeto Político Pedagógico - PPP, que na época passava por um processo de atualização. Nesse ponto do estágio, a análise se ateve ao Marco Referencial que traz aspectos que constroem a identidade do educandário, o Diagnóstico que se debruça sob a realidade da escola e o Plano de Ação que estava se organizando no momento da realização do estágio a fim de ser inserido de fato no PPP. Foi possível observar as reuniões para a seleção dos itinerários que se adequavam aos desafios enfrentados pela escola.

Conhecendo o PPP, foi plausível visualizar como a instituição se organiza antes de refletir como tais fatores estariam na prática. Isso implica elencar que para além de dados como quantidade de alunos por turma, horários demarcados pelas séries a serem levadas para o recreio, número de pátios, salas e banheiros, o documento interno trazia citações dos autores Paulo Freire e Manuel Bandeira. Nesse sentido, tais trechos reforçavam o quanto o ambiente escolar precisa se abrir às possibilidades de forma a abraçar os discentes numa perspectiva de humanização.

Durante a análise do calendário foi perceptível a verificação de cinco sábados letivos no ano corrente assim como a diferenciação entre dia letivo e dia escolar. Mediante a dúvida, a supervisora informou que dia escolar é aquele que ocorre sem a presença do aluno, ou seja, capacitações entre professores e equipe pedagógica, já os dias letivos são os que correspondem 
às aulas e eventos escolares nos quais é participante a figura do aluno.

Tendo em vista que tais observações se passaram na biblioteca, a programação dos alunos que iam semanalmente trocar livros foi analisada de perto junto às bibliotecárias. Dessa prática, foi verificado que os alunos enfocam suas preferências mediante a estante correspondente a série estudada, comparecendo a biblioteca, semanalmente, em grupos de sete a oito por turma ( $4^{\circ}$ e $5^{\circ}$ ano). Tais obras literárias podem ser visualizadas como livros de contos, poemas e crônicas que trazem em sua estrutura imagens relacionadas ao conteúdo. Em relação aos livros didáticos, foi informado que os educandos podem levar para casa a fim de realizar atividades, mas, que estando sem utilizá-lo, são guardados no armário de cada sala de aula.

Outra atividade tida como suporte e contribuição do estágio curricular supervisionado para a escola foi o auxílio no grampeamento das provas de Português, Geografia e Matemática. Como podemos perceber, é mais um reflexo do distanciamento entre universidade e escola tendo em vista que o desempenho de tal atividade não corresponde aos tópicos a serem desenvolvidos no estágio de caracterização presentes no guia de operacionalização do estágio. Nesse enfoque, as folhas de avaliação eram dispostas em uma mesa e seguindo a ordem das questões eram devidamente grampeadas, visto que seriam aplicadas na semana seguinte. Após esse procedimento, as provas eram entregues nas respectivas turmas a serem guardadas no armário subjacente a cada sala de aula. Apesar de essas tarefas corriqueiras não estarem dispostas nas orientações do estágio - etapa de caracterização - elas foram importantes para entender a dinâmica da escola em relação ao processo de ensino aprendizagem, o papel que cada profissional exerce dentro da escola, as limitações estruturais, entre outros aspectos.

\section{Hora Cívica e Supervisão do Recreio: Relações Interpessoais em Ação}

Com a aproximação do dia da independência, iniciaram-se na escola os preparativos para o desfile de sete de setembro. Além da apresentação de um jogral ministrado pelas bibliotecárias acerca do marco histórico, o Hino Nacional foi treinado para ser exposto em libras com o auxílio da intérprete. Para tais momentos, as turmas eram convocadas a se reunirem no espaço entre o portão principal e a escadaria de acordo a programação. Dessa forma, compareciam para treinamento conforme o dia marcado apenas as turmas de primeiro nano para segunda-feira, segundo ano para terça e assim sucessivamente. Somente na sexta-feira que antecedeu o evento que todas as turmas se reuniram no pátio para treinar todas as apresentações.

No dia do evento supracitado, o pátio foi palco para alunos trajados com roupas da fanfarra, colegial, esportistas, princesas, bailarinas, catopês, símbolo regional que protagoniza as 
festas tradicionais de Agosto na cidade de Montes Claros (MACHADO, 2008) enquanto os demais discentes desfilavam com calça jeans e uniforme da escola. As contribuições que foram possíveis a partir da realização do estágio compreendeu-se na organização das alunas que iriam à frente da fanfarra bem como na entrega dos trajes de bailarina que vinham identificados e sob medida.

Tendo em vista a demarcação de quinze minutos dedicados ao recreio, a vice-diretora solicitou um acompanhamento conjunto a fim de seguir o movimento dos alunos, em especial os do quinto ano visto que correspondiam a turmas maiores. Enquanto muitos se sentavam de lado com seus respectivos vínculos de amizade, outros se encaminhavam para a fila da merenda buscando lugares nas mesas colocadas de frente para o refeitório. A falta de mais profissionais integrados neste momento do turno escolar mostra-se agravante quando nos deparamos com os meninos levando objetos como garrafinhas de suco e lancheiras para dentro do banheiro masculino fazendo com que as meninas esperassem alguém passar para pedir que pegasse de volta. Com isso, iniciavam-se corridas no pátio íngreme pela superlotação de alunos e, consequentemente, o desequilíbrio de alunos alheios a este evento. Mais uma vez foi perceptível como a escola é viva e vibrante.

Não obstante, os professores responsáveis pelas turmas presentes no recreio mostraram-se distantes, mantendo-se afastados dos círculos agitados, supervisionando os que lanchavam sentados às mesas da cantina. A vice-diretora transitava o tempo todo entre os círculos, levando os discentes que mais perturbavam os colegas para o pátio superior no qual se tinha uma visão ampliada da sala dos professores. Dessa forma, eram mantidos neste pátio até o final do intervalo, acompanhando a turma de volta para sala.

Além destes eventos, a ausência de um profissional fixo para acompanhamento de crianças autistas no $5^{\circ}$ ano foi uma percepção oriunda da necessidade de apoio na realização da prova de matemática. Isso implica afirmar que, como não havia estagiários observando a aula no dia da avaliação, solicitaram que acompanhasse duas crianças dando orientações, não respostas, a fim de que não se dispersassem do objetivo daquele mecanismo avaliativo. Apesar de ter sido uma experiência nova, surge a preocupação quanto ao desenvolvimento destes, visto que a professora sozinha não dá conta de supervisionar trinta crianças e ainda voltar-se para os dois com a doação de um tempo e atenção que as obrigações diárias não disponibilizam.

Ao observar esse movimento da escola, foi impossível não pensar no quanto já havia vivenciado aqueles momentos, no papel de aluna, e o quanto era diferente analisar esses movimentos na condição de docente em processo de formação. 


\section{Palestras e Reuniões no Educandário: Projeção de Perspectivas para o Ambiente Escolar}

O pátio que contempla o recreio dos alunos também é usado para fins de palestras e reuniões que agreguem um público maior. Nesse sentido, em um dos dias de observação, após o momento dedicado ao lanche, os alunos foram convocados a comparecer neste espaço para assistir uma palestra sobre a importância da robótica. Para tal, os discentes se sentaram no chão, as professoras nos bancos que os circundavam, enquanto uma mesa foi colocada à frente com vários equipamentos como drone, um robô, que segundo o palestrante foi construído com a integração de seis faculdades e que mais tarde fora apresentado dançando o que gerou admiração e entusiasmo por parte da comunidade escolar. Ainda que o microfone fosse baixo, os palestrantes buscaram resumir suas falas com a finalidade de serem compreendidos.

Além das demonstrações acima mencionadas, os dados apontados pelo emissor acerca da tecnologia que se emprega para construir as máquinas e a discussão acerca da possibilidade de, em um futuro próximo, os drones atuarem no Brasil como profissão, fomentou forte interesse nos alunos. Isso se verificou em especial pelo estranhamento conjunto ao ser relatado que o robô da Vinci ${ }^{1}$ já realiza cirurgias no coração, mesmo que sua implementação seja de alto custo, devido ao tempo de operação reduzir cinquenta por cento, não descartaram a hipótese de empresas privadas aderirem a nova tecnologia. Esse tipo de atividade acenou para a importância de a escola procurar fora do espaço da sala de aula, meios de incentivar seus alunos a buscar conhecimento útil a eles mesmos e a sociedade como um todo. Além disso, foi importante por demonstrar a existência de profissões que não fazem parte de nossa realidade cotidiana.

Para dar continuidade ao processo de atualização do PPP, iniciaram-se reuniões em prol da análise dos itinerários encaminhados pelo Ministério da Educação visando adequar os planos de ação mediante a realidade escolar. Sob essa perspectiva, em um primeiro momento foi realizada uma reunião de professores para discutir os itinerários que mais se inclinavam para as dificuldades enfrentadas pela escola. Para cada itinerário, total de oito, dez ações estavam inseridas para que duas fossem escolhidas, com vistas a serem efetivadas.

Dentre as ações escolhidas por concordância unânime, estavam tentativas de levarem os pais mais vezes para o cenário no qual seus filhos estudam, estabelecer rodas de conversa com alunos e pais, desenvolver capacitações para toda equipe escolar para auxiliar os alunos no

\footnotetext{
${ }^{1}$ Denominado em inglês de The da Vinci Surgical System, o robô atua por intermédio do clínico responsável. Este, em uma mesa de comando age através dos quatro braços do dispositivo que também possui câmera. Enquanto o robô da Vinci utiliza tesoura e bisturi, o médico visualiza pela câmera o local em que deve ocorrer o procedimento.
} 
viés da inclusão e buscar nas parcerias com as faculdades o apoio psicológico realizado por acadêmicos estagiários dado a diversidade de eventos que coexistem com os discentes e que influenciam no rendimento escolar.

No dia do Currículo, reunião ocorrida no sábado letivo de vinte e um de setembro, as redes estaduais se debruçaram sobre o Projeto Político Pedagógico e os itinerários já reduzidos de ações para inferência da percepção dos pais dos alunos. Nesse contexto, perguntas foram entregues a algumas pessoas presentes, professores e pais, referindo-se aos conteúdos que iriam ser abordados na reunião como "você acha importante os pais frequentarem a escola?" e "a escola é inclusiva?" com o intuito de iniciar a discussão.

Embora o encontro de pais e mestres tenha ocorrido em um sábado, o horário estipulado no turno da manhã dificultou a participação de mais de cinquenta por cento destes. Contudo, os que estavam presentes participaram ativamente durante os pontos norteadores, em especial no momento da dinâmica de grupos. Isso implica descrever que os itinerários foram divididos por grupos compostos por um a dois pais, um aluno, e um professor da escola a discutir com a equipe a importância daquele itinerário em comparação com os outros listados. Vale ressaltar que uma dinâmica envolvendo o assunto do itinerário também foi anexada às informações do bloco.

Voltando ao grupo do qual este estudo relata, o itinerário trazia a problemática da violência na escola. Nesse contexto, dos dez planos de ação propostos pelos itinerários, a leitura realizada pela professora foi se adequando àquelas que mais se encaixavam na realidade perceptível na instituição. Para isso, a dinâmica proposta baseava-se na construção de duas árvores no quadro negro, de um lado os aspectos positivos, ou seja, sem a ocorrência da violência e do outro os aspectos negativos, o impacto desta no cenário escolar. As palavras que completavam a copa dessas árvores foram sendo colocadas à medida que os participantes iam lembrando e comunicando a professora, como impunidade física e insegurança para pontos negativos e proximidade entre família/ escola tal como interatividade para pontos positivos.

Assim que os dois planos de ação foram escolhidos a partir do consenso entre os membros do grupo responsável pelo itinerário, todos retornaram ao pátio para relatar brevemente como se deu a experiência e os planos escolhidos. Dessa forma, foram elencadas as necessidades que o educandário possui: disponibilizar estagiários para reforço, organização da biblioteca, presença dos pais na escola (participação efetiva), rodas de conversa para viabilizar discussões acerca da depressão e ansiedade, elaborar planejamentos interdisciplinares, inclusão e diversidade no sentido de capacitar professores e demais servidores para melhor 
acompanhamento dos alunos, necessidade de integrar toda a comunidade escolar, ter uma recomendação mais clara sobre a sala de recurso e sua utilização, detectar atitudes de discriminação, promover palestras que integrem família, conselho tutelar e escola; ambiente participativo a fim de fortalecer o espírito de liderança, aperfeiçoamento e descoberta de habilidades, disseminar o que for decidido nas reuniões e entre os membros do colegiado, curso de especialização para melhorar atuação de forma a aprimorar as práticas pedagógicas e valorizar a figura do professor.

Portanto, após esses procedimentos, foi comunicado que os planos de ação são inseridos na plataforma Itinerários para ciência da Secretaria de Educação enquanto a supervisão finaliza o Projeto Político Pedagógico com a inserção dos mesmos.

Voltando-se para a palestra intitulada "Espaço de Reflexão e Acolhimento", última das atividades analisadas durante o período de estágio de caracterização da escola, em um primeiro momento foi servido um café inicial seguido por uma oração e logo depois todos se dirigiram a sala marcada para apresentação. Nesse segundo momento, a palestrante iniciou a apresentação com slides, mas, dividia o tempo com dinâmicas entre diferentes temas. Nesse sentido, explicou a importância de discutir sobre autoestima, em não buscar felicidade em coisas e pessoas tendo em vista que ela reside dentro de cada um, que ser educador não é para todos dado a doação com que tais profissionais atuam no desenvolvimento do indivíduo.

Além dos fatores acima mencionados, os participantes foram convidados a, de pé, fazerem um círculo e na pessoa que estava a frente realizar uma massagem para aliviar as tensões. Depois de explanar um pouco mais sobre terapias holísticas e canalização de energia, a palestrante solicitou que cada um fechasse os olhos e se imaginasse em frente a duas portas, uma azul e uma rosa, descrevendo logo mais o que tinha por trás de cada uma delas. Foi unânime quando questionados a tranquilidade relatada que tal atividade despertou nos presentes. Finalizando a palestra, foram distribuídos colares carnavalescos enquanto uma música era colocada a fim de que, tal como sugere o nome "Abra suas Asas, solte Suas Feras" cada participante não se esquecesse de olhar para si e buscar paz interior, objeto discutido em todos os momentos da palestra.

Ao vivenciar essas palestras e/ ou eventos promovidos pela escola foi nítida a preocupação da comunidade escolar em se empenhar para contribuir cada vez mais com o ensino aprendizagem dos alunos. Por mais que em relação ao estágio se mostrassem distantes, o comportamento era outro quando se tratava de refletir sobre seus papéis de professores e buscar suporte na família para que atitudes necessárias pudessem ser adotadas. Tal afirmação pauta-se 
nos constantes bilhetes que os alunos levavam para casa em prol de uma articulação melhor entre família e escola. Diante disso, pensar projetos que também fizessem este percurso entre universidade e escola seria fundamental e fomentaria o interesse dos discentes, uma vez que a presença nas reuniões e participação dos professores era considerável e contava com quase toda equipe escolar.

\section{Considerações Finais}

Com a finalização da etapa de caracterização do Estágio Curricular Supervisionado, torna-se perceptível o quanto o educandário apresenta relações que tendem a integrar família e escola assim como atuar em prol do desenvolvimento dos alunos. As constantes atividades discorridas durante o período de caracterização da escola, tais como eleições de colegiado, preparação para a semana de provas, informações acerca do desfile de sete de setembro, apoio para montar cesta básica destinada a famílias carentes evidenciadas pelo comportamento de alunos, entre outras, eram sempre informadas por meio de bilhetes e avisos visando à participação dos pais. Logo, demonstrava que a relação estabelecida entre a comunidade escolar ultrapassava os limites da sala de aula, numa tendência de humanizar o processo de ensino aprendizagem.

Além disso, desta experiência, se coloca a necessidade de diminuir a distância entre universidade e escola como uma linha cada vez mais tênue propondo-se a não fixar na estrutura cognitiva do estagiário a ideia de que o educandário não é o seu lugar. Desta forma, reflete-se o quanto a disciplina Estágio Curricular Supervisionado é essencial para os professores em formação na medida em que se verificam na prática suas contribuições para a Escola. Sob essa perspectiva, a titulo de sugestão, o ideal é que diretoras e vice-diretoras pudessem realizar capacitações dispostas pela universidade através das coordenações de estágio visando compreender nitidamente o papel a ser exercido em cada etapa para que o acadêmico se sinta engajado quanto às ações a serem desenvolvidas na escola.

Sobre as desconfianças iniciais em relação ao fato de caracterizar a escola ser algo simples e rápido, se mostrou uma experiência que ia muito além do tempo que correspondia à carga horária. Isso implica enfatizar o quanto foi importante conhecer a escola e refletir sobre o espaço, como os alunos se organizavam durante o turno de suas aulas, como o reforço ocorria concomitante a aula no qual o aluno sentava do lado de fora acompanhado por estagiárias de outros projetos, a relação das bibliotecárias com os alunos tanto no empréstimo de livros como suporte para as salas de aula. Com isso, enfatizamos o quanto a caracterização possibilitou a 
percepção de que a escola, apesar de todos os desafios que enfrenta diariamente, é um organismo vivo, sujeito a mudanças e que se movimenta para uma melhor participação na vida dos alunos, ultrapassando os muros que a rodeiam.

\section{Referências}

COUTO, Ligia Paula. Didática da Língua Espanhola no Ensino Médio. São Paulo: Cortez, 2016.

FAZENDA, Ivani Catarina Arantes. O Papel do Estágio nos Cursos de Formação de Professores. In: PICONEZ, Stela C. Bertholo; FAZENDA, Ivani Catarina Arantes. A Prática de Ensino e o Estágio Supervisionado. 2. ed. Campinas: Papirus, 1994. Cap. 3. p. 53-62.

LIMA, Maria Socorro Lucena. Reflexões sobre o Estágio: Prática de Ensino na Formação de Professores. Revista Diálogo Educacional, Curitiba, v. 8, n. 23, p.195-205, 2008. Quadrimestral.

MACHADO, Paula. Os Catopês de Minas e suas Tradições ainda Marcam a História do Estado. Disponível em: <<https://onorte.net/montes-claros/os-catop\%C3\%AA >>

Acesso em: 12 nov. de 2019.

RODRIGUES, Valéria Daiane Soares. Relevância do Estágio Curricular Supervisionado na Formação de Professores. Ciranda, Montes Claros, v. 1, n. 1, p.43-53, 2017. Anual.

UNIMONTES. Projeto Político Pedagógico do Curso de Licenciatura em Letras Espanhol da Universidade Estadual de Montes Claros, 2015.

VEJA como funciona o da Vinci, robô cirurgião de R \$ 6 milhões. Setor Saúde: Tecnologia e Inovação. 15 de maio de 2015. Disponível em: 〈https://setorsaude.com.br/veja-como-funcionao-da-vinci-robo-cirurgiao-de-r-6-milhoes/>. Acesso em: 24 de jul. de 2020.

Artigo recebido em: 22/07/2020. Artigo aceito em: 19/08/2020. 